\title{
Preparation and characterization of aluminum doped zinc oxide (AZO) nanorods
}

\author{
V BALAPRAKASH ${ }^{1, *}$, P GOWRISANKAR $^{1}$, R RAJKUMAR $^{2}$ and S SUDHA ${ }^{1}$ \\ ${ }^{1}$ Hindusthan College of Arts and Science, Coimbatore 641 028, India \\ ${ }^{2}$ CSIR-National Geophysical Research Institute, Hyderabad 500 007, India \\ e-mail: km.balaprakash@gmail.com
}

MS received 24 March 2016; accepted 14 January 2018; published online 23 May 2018

\begin{abstract}
Aluminum doped Zinc Oxide (AZO) nanorods with 1at.\% aluminum content were prepared by Solgel spin coating technique. The structural and topographical properties are studied using X-Ray Diffraction (XRD) technique and Atomic Force Microscopy (AFM), respectively. Higher intensity Zinc Oxide (ZnO) peak (002) is observed in 1at.\% aluminum doped nanorod with $50 \mathrm{~s}$ spin coated sample underwent $300^{\circ} \mathrm{C}$ of annealing temperature. Morphologic, compositional and crystallographic information of the samples are predicted using Transmission Electron Microscopy (TEM), the $600 \mathrm{~nm}$ long nanorod with an aspect ratio of 10 is obtained for $20 \mathrm{~s}$ and $50 \mathrm{~s}$ spin coating time.
\end{abstract}

Keywords. ZnO nanorods; nanoparticle; sol-gel; XRD; AFM; TEM.

\section{Introduction}

Zinc Oxide $(\mathrm{ZnO})$ is a versatile material. It has a wide band gap which means a higher breakdown voltage, ability to sustain large electric fields, lower electronic noise, and high temperature and high power operation. Further, the band gap of $\mathrm{ZnO}$ can be tuned easily by doping and constricting the particle size. Zinc Oxide is an n-type semiconductor that means the majority carriers are electrons. These electrons have a mobility of $\sim 2000 \mathrm{~cm}^{2} / \mathrm{V}$-s at $80 \mathrm{~K}$ and it strongly varies with temperature. However, the doping level can be altered with specific choice of dopants which make $\mathrm{ZnO}$ more $\mathrm{n}$-type or $\mathrm{p}$-type in character. High heat capacity $\left(\mathrm{C}_{\mathrm{p}}=40.3 \mathrm{~J} / \mathrm{mol}-\mathrm{K}\right)$ and heat conductivity $(\mathrm{k}=$ $0.6-1 \mathrm{~W} / \mathrm{cm}-\mathrm{K})$, low thermal expansion $(\alpha=2.5-4.3 \times$ $10^{-6} / \mathrm{K}$ ) and high melting temperature (at $1974^{\circ} \mathrm{C}$ decomposes) of $\mathrm{ZnO}$ are beneficial for many applications in electronic and optoelectronic devices such as ultraviolet light-emitters, piezoelectric transducers, solar cells, nanoscale sensors and actuators [1-6].

$\mathrm{ZnO}$ nanostructures can be synthesized with variety of methods including MOCVD, thermal evaporation, molecular beam epitaxy (MBE), electrochemical deposition, spray pyrolysis, and sol-gel. Among these methods, the solgel technique is the simplest and least expensive one [7-11]. In several studies, the structural and optical properties of Aluminum doped Zinc Oxide (AZO) nanorods could be obviously improved by optimized deposition conditions and controlled doping. The primary aspiration of

*For correspondence this work is to examine the influence of the preparation conditions on structural and optical properties of AZO nanorods prepared by sol-gel spin coating method. The structural characteristics have been studied using X-Ray Diffraction (XRD). The morphological features have been studied using Scanning Electron Microscopy (SEM) and Transmission Electron Microscopy (TEM). Two-dimensional topographic information of nanorods are investigated using Atomic Force Microscopy (AFM).

\section{Experimental details}

Zinc acetate dihydrate $\left(\mathrm{C}_{4} \mathrm{H}_{6} \mathrm{O}_{4} \mathrm{Zn} \cdot 2 \mathrm{H}_{2} \mathrm{O}\right)$ and diethanolamine $\left(\mathrm{C}_{4} \mathrm{H}_{11} \mathrm{NO}_{2}\right)$ are used as a precursor material and the solvent, respectively. Diethanolamine (DEA) was first dissolved in isopropanol (iProH), Zinc acetate dihydrate (ZnAc) was added under stirring, and heated under reflux for $1 \mathrm{~h}$ at $70^{\circ} \mathrm{C}$. Zinc acetate was dissolved in DEA by the molar ratio of $1(\mathrm{DEA} / \mathrm{Zn}=1)$. Flowchart showing the procedure for preparing the aluminum doped $\mathrm{ZnO}$ nanorods in figure 1 .

Doping of the solution was obtained by adding a $0.2 \mathrm{M}$ solution of aluminum nitrate in ethanol. The molar ratio of dopant in the solution $(\mathrm{Al} / \mathrm{Zn})$, varied between $0.5 \%$ and $5 \%$. Isopropanol was added to adjust the solution concentration to $0.5 \mathrm{Mol} / \mathrm{L}$ of $\mathrm{ZnAc}$. The molar ratio of DEA to $\mathrm{ZnAc}$ was maintained 1 at. $\%$. The solution was stirred at $70^{\circ} \mathrm{C}$ for $2 \mathrm{~h}$ to yield a clear and homogeneous solution, which served as the coating solution after cooling to room temperature. The coating was usually made one or two days 


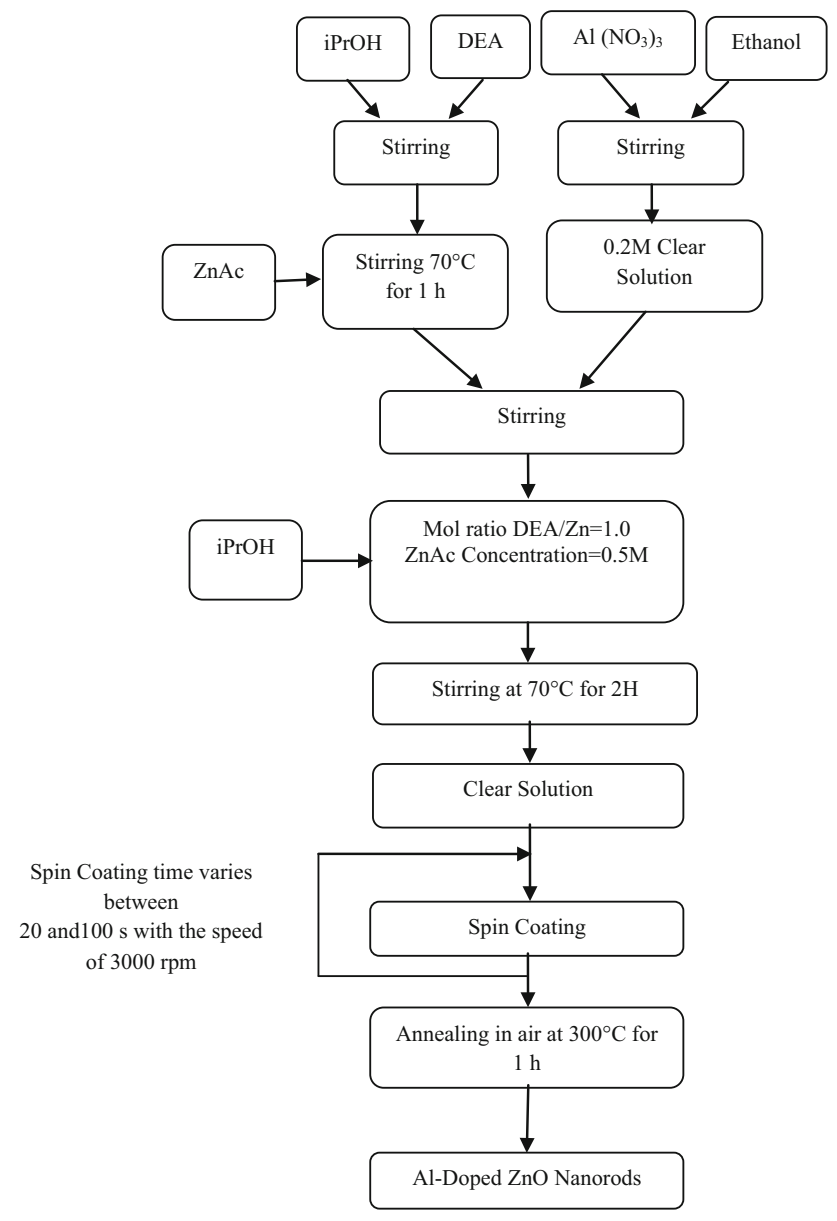

Figure 1. Flowchart showing the procedure for preparing the aluminum doped $\mathrm{ZnO}$ nanorods.

after the solution was prepared, glass substrate was used for coating. To make different density of $\mathrm{Zn}$ seeds which will result in difference in grown nanorods density, spin coating time was altered as $20 \mathrm{~s}, 50 \mathrm{~s}$ and $100 \mathrm{~s}$ throughout the process and spin speed remained same as $3000 \mathrm{rpm}$. After spin coating, a brief annealing at $300^{\circ} \mathrm{C}$ for $1 \mathrm{~h}$ was carried out to prepare the samples.

\section{Results and discussion}

\subsection{X-Ray Diffraction analysis}

The X-Ray Diffraction analysis (XRD) was used to investigate the physicochemical process involved in the sol-gel deposition of AZO nanorods. All peaks were well-matched with hexagonal structure of $\mathrm{ZnO}$ and no other impurity peaks were observed in XRD pattern which shows the purity of the nanoparticle formation. XRD results reveal that nanorods have a polycrystalline hexagonal wurtzite structure with well-developed crystallinity. The crystalline volume of $1 \mathrm{at} . \%$ aluminum doped nanorods are calculated from its most intense peak (101) of $\mathrm{ZnO}$, its value is around

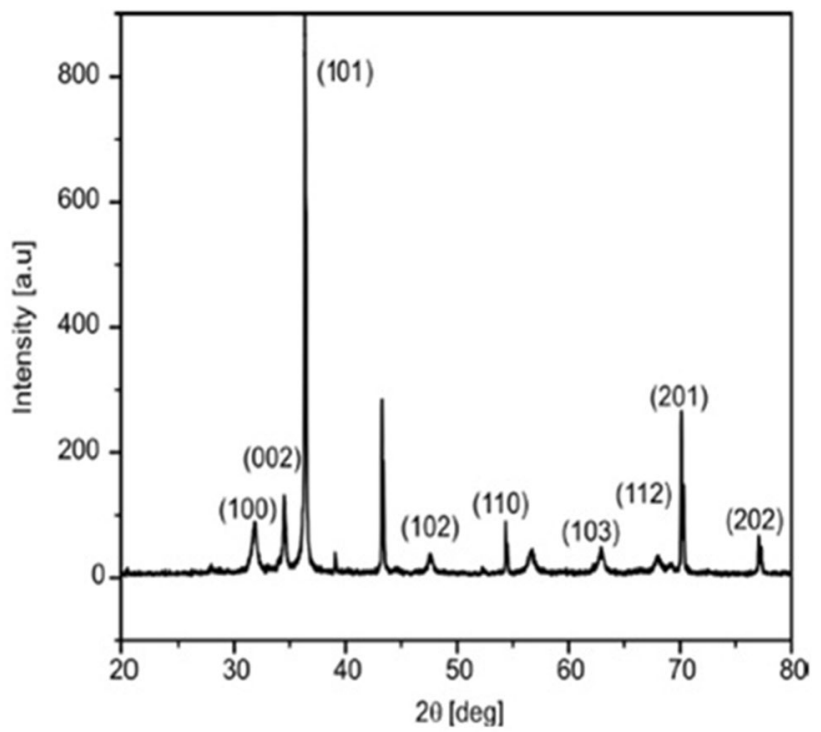

Figure 2. XRD patterns of the 1at.\% aluminum doped nanorods.

$26.2 \mathrm{~nm}$. The XRD patterns of these nanorods with 1at.\% aluminum contents are shown in figure 2 .

\subsection{Atomic Force Microscopy (AFM) analysis}

The AFM is useful for obtaining two and three-dimensional topographic information. The surface morphology of solgel derived AZO nanorods was evaluated by AFM. Figure 3(a)-(c) shows the micrograph of 1at.\% Aluminum doped sample with $20 \mathrm{~s}, 50 \mathrm{~s}$ and $100 \mathrm{~s}$ of spin coating time was annealed at $300^{\circ} \mathrm{C}$ ( $2 \mathrm{D}$ view). As can be observed, the film is constituted of closely-packed fluffy nanoparticle dispersed all over the surface, with the presence of nano pores. The particle size measured is $24 \pm 15 \mathrm{~nm}$, and the
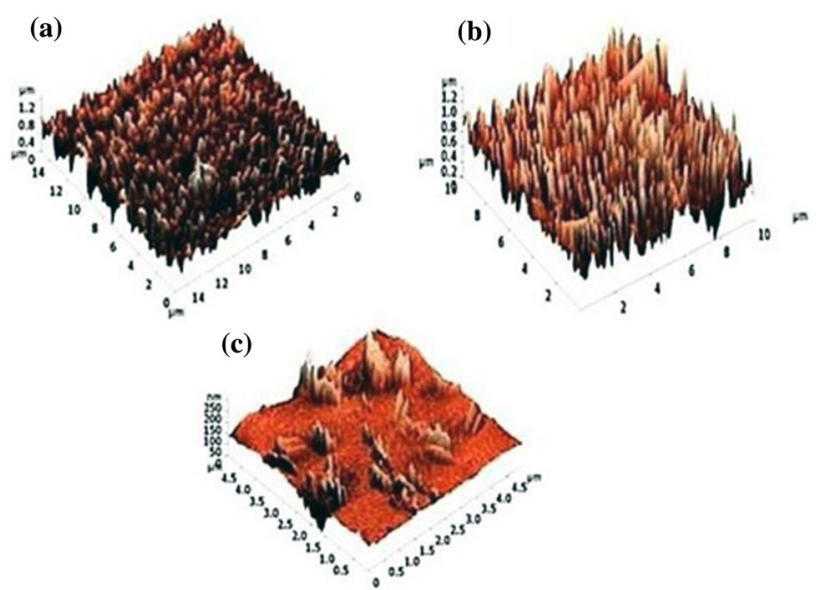

Figure 3. 2D AFM image of 1at.\%. Aluminum doped $\mathrm{ZnO}$ Nanorods prepared with spin coating at $3000 \mathrm{rpm}$ for (a) $100 \mathrm{~s}$, (b) $50 \mathrm{~s}$ and (c) $20 \mathrm{~s}$. 

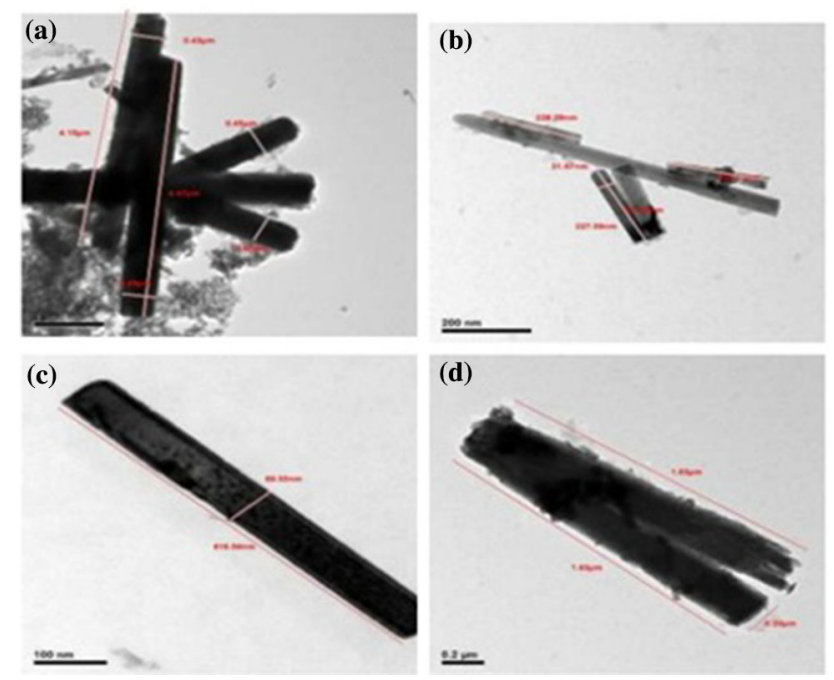

Figure 4. TEM image of AZO nanorods prepared with spin coating at $3000 \mathrm{rpm}$ (a), (b) for $20 \mathrm{~s}$, (c) for $50 \mathrm{~s}$ and (d) for $100 \mathrm{~s}$.

surface of the films is very smooth, since the calculated roughness is $1.5 \mathrm{~nm}$ for the nanorods.

\subsection{Transmission Electron Microscopy (TEM) analysis}

TEM utilizes energetic electrons to provide morphologic, compositional and crystallographic information of samples. Figure 4(a)-(c) illustrates TEM image of AZO nanorods prepared with various spin coating time at $3000 \mathrm{rpm}$ for $20 \mathrm{~s}, 50 \mathrm{~s}$ and $100 \mathrm{~s}$. Figures reveal that all nanorods are of aspect ratio with $8-10$, but their dimension purely depends on the preparation condition. $20 \mathrm{~s}$ and $50 \mathrm{~s}$ spin coated nanorods are bigger and thicker than $100 \mathrm{~s}$ spin coated nanorods. The $600 \mathrm{~nm}$ long nanorod with an aspect ratio of 10 is obtained for $20 \mathrm{~s}$ and $50 \mathrm{~s}$ spin coating time.

\section{Conclusions}

The AZO nanorods were fabricated on glass substrate. Furthermore, AZO nanorods were characterized by XRD, AFM and TEM. The X-ray diffraction technique reveals that, the higher intensity of the (002) peaks are observed in aluminum concentration of 1 at.\% AZO nanorods, when the annealing temperature was maintained at $300^{\circ} \mathrm{C}$. According to the AFM results, 1 at.\% aluminum doped film exhibits a porous microstructure and the spherical crystalline particle size of approximately $24 \pm 15 \mathrm{~nm}$. TEM results showed that $20 \mathrm{~s}$ and $50 \mathrm{~s}$ spin coated AZO nanorods are bigger than others and also it yielded $600 \mathrm{~nm}$ long rod.

\section{References}

[1] Bao J, Zimmler M A, Capasso F, Wang X and Ren Z F 2006 Broadband $\mathrm{ZnO}$ single-nanowire light-emitting diode. Nano Lett. 6(8): 1719-1722

[2] Cheng H C, Chen C F and Tsay C Y 2007 Transparent ZnO thin film transistor fabricated by sol-gel and chemical bath deposition combination method. Appl. Phys. Lett. 90(1): 012113

[3] Sahay P P and Nath R K 2008 Al-doped zinc oxide thin films for liquid petroleum gas (LPG) sensors. Sens. Actuators B: Chem. 133(1): 222-227

[4] Jiaqiang X, Yuping C, Yadong L and Jianian S 2005 Gas sensing properties of $\mathrm{ZnO}$ nanorodes prepared by hydrothermal method. J. Mater. Sci. 40(11): 2919-2921

[5] Young S J, Ji LW, Fang T H, Chang S J, Su Y K and Du X L $2007 \mathrm{ZnO}$ metal-semiconductor-metal ultraviolet photodiodes with Pd contact electrodes. Acta Mater. 55(1): 329-333

[6] Lamb D A and Irvine S J C 2004 Growth properties of thin film $\mathrm{ZnO}$ deposited by MOCVD with n-butyl alcohol as the oxygen precursor. J. Cryst. Growth. 273(1): 111-117

[7] Zu P, Tank Z K, Wong G K L, Kawasaki M, Ohtomo A, Koinuma H and Segawa Y 1997 Ultraviolet spontaneous and stimulated emissions from $\mathrm{ZnO}$ microcrystalline thin films at room temperature. Solid State Commun. 103(8): 459-463

[8] HiromitsuKozuka and Toshinobu Yoko 1998 Sol-Gel preparation of transparent and conductive aluminum-doped zinc oxide films with highly preferential crystal orientation. J. Am. Ceram. Soc. 81(6): 1622-1632

[9] Cossement D and Streydio J M 1985 Fabrication of ZnO polycrystalline layers by chemical spray. J. Cryst. Growth 72(1-2): 57-60

[10] Nishino J, Kawarada T, Oshio S, Saitoh H, Maruyama K and Kamata K 1997 Conductive indium-doped zinc-oxide films prepared by atmospheric-pressure chemical-vapor-deposition. J. Mater. Sci. Lett. 16(8): 629-631

[11] Vinay Gupta and Abhai Mansingh 1996 Influence of postdeposition annealing on the structural and optical properties of sputtered zinc oxide film. J. Appl. Phys. 80(2): 1063-1073 